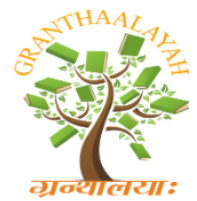

\author{
INTERNATIONAL JOURNAL OF
GRANTHAALAYAH \\ A knowledge Repository
}

Science

\title{
THE PREVALENCE OF PSYCHIATRIC MORBIDITY (SEVERE DEPRESSION \& ANXIETY) AMONG ADOLESCENT SCHOOL GIRLS KHARTOUM-SUDAN
}

\author{
Nadia Mahmoud Ali Abuzied ${ }^{* 1}$, Kamil M Ali ${ }^{2}$ \\ ${ }^{1}$ Planning and Policy and Health Research Department /Continuous Professional Development \\ Directorate, Federal Ministry of Health, Khartoum, Sudan \\ ${ }^{2}$ Department of Community Medicine, Faculty of Medicine, University of Khartoum, Khartoum
}

\begin{abstract}
Background - Psychosomatic health of adolescent girls at crossroads of childhood and mature adulthood, may lead to various health problems in future. To measure the prevalence and identify factors associated with psychiatric morbidity \& psychosomatic symptoms among adolescent secondary school girls in Khartoum.

Methods - This 'Study' was conducted, in three secondary schools of Khartoum North. The Simple Random Sampling Technique was applied to select three schools from the spot map of Khartoum North for this study, and 491 girl students in the adolescent age group were selected from the completed updated list of students from the enrollment registers in these schools.

Results - according to the cut-off point ( $\geq 24$ in the G.H.Q -28) findings showed that the prevalence of psychiatric morbidity (severe depression and anxiety) was $60.89 \%$ among the adolescent secondary school girls while the psychosomatic disorder was $34.62 \%$. The psychosomatic disorder was found to be significant $(\mathrm{P}<0.05)$ with the following three factors: a) late $(18-19 \mathrm{yrs}$. $)$ adolescent age, $(61.30 \%)$, chi- square $=18.611, \mathrm{df}=1, \mathrm{O} . \mathrm{R}=0.435617, \mathrm{CI} 95 \%=(0.276629,0.685981)$; b) physicals abuse $(39 \%)$ chi- square $=22.34, \mathrm{df}=1, \mathrm{O} . \mathrm{R}=0.281, \mathrm{CI} 95 \%=(0.172871,0.458281)$ and $\mathrm{c})$ verbal abuse $(72 \%)$ chi- square $=21.86, \mathrm{df}=1, \mathrm{O} . \mathrm{R}=0.433, \mathrm{CI} 95 \%=(0.27331,0.688)$. A borderline significant was seen with the family moderate (40\%) and low income (40\%), chi- square $=5.09$, $\mathrm{df}=2$, O.R $=(0.839,0.799), \mathrm{CI} 95 \%=((0.508247,0.503899),(1.755645,1.426668))$. However, no significance was there in relation to marital status (married 83.5\%), chi- square $=2.324, \mathrm{df}=1$, $\mathrm{O} . \mathrm{R}=1.06, \mathrm{CI} 95 \%=(0.586947,2.197218)$, mothereducation(elementary61.76\% $)$ chisquare $=1.692, \mathrm{df}$ $=2, \mathrm{O} . \mathrm{R}=(1,0.951), \mathrm{CI} 95 \%=((0.385528,0.554214),(2.674766,1.626457))$ and further education (high level $73 \%)$ chi- square $=3.17, \mathrm{df}=2, \mathrm{O} . \mathrm{R}=(1.282,1.024), \mathrm{CI} 95 \%=((0.354603,0.55087)($, 4.49567, 1.903074)).
\end{abstract}

Conclusion - Despite the fact that there is no significant $(\mathrm{P}>0.05)$ relation between the fathers' level of education and the occurrence of psychosomatic however, the odds ratio of disease is $28 \%$ higher among the girls whose fathers were illiterate in comparison to the girls whose fathers were of high level of education. among adolescent school girls.

Keywords: GHQ-28; Cut Off Point 24; Psychosomatic Health; Sub -Scales of GHQ. 
Cite This Article: Nadia Mahmoud Ali Abuzied, and Kamil M Ali. (2020). "THE PREVALENCE OF PSYCHIATRIC MORBIDITY (SEVERE DEPRESSION \& ANXIETY) AMONG ADOLESCENT SCHOOL GIRLS KHARTOUM-SUDAN." International Journal of Research Granthaalayah, 8(1), 165-175. https://doi.org/10.29121/granthaalayah.v8.i1.2020.263.

\section{Introduction}

In the era of psychiatric morbidity and psychosomatic disorder, much attention has been paid to migratory laborers and bridge population, because of their overt risky behavior, although little attention has been paid to other parts of the population .psychiatric morbidity and psychosomatic disorder are increasing at a faster rate globally in the early adult population. Moreover, as they are at the crossroad of childhood and mature adulthood, many diversions come in the way of their rational thinking. They go for experimentation of different types. Any significant difference in their perception with regard to physical and mental development in their own body also needs to be explored.This study intended to verify the prevalence of the psychosomatic disorder, in girls students in the adolescent age groups in Khartoum .Many adolescents see physicians for diagnosis and treatment of symptoms that are found to have little or no organic basis. Definition, epidemiology, diagnosis, and management of psychosomatic symptoms are presented, with special attention to recurrent abdominal pain, which is one of the most common somatoform syndromes Also problems arise from relation to parents or peers. Moreover, strained relations were more strongly associated with health complaints, especially psychosomatic complaints, than were supportive relations. This applied to relationships with parents as well as with peers in school. (BrolinLaftman\&Ostberg, 2006). Research from several countries indicates that psychosomatic disorder tend to co-exist rather than occur singularly and could impose limitations on daily living and participation in school life.(Colette Kelly2010)reported the need for better understanding of the nature, extend, and possible causes of frequent psychosomatic symptoms among school children in Ireland, Social environment and behavioral factors need further consideration. Exploring time trends in psychosomatic symptoms by gender is also worth pursuing in light of the recent economic, societal, and educational changes in Ireland.

\section{Materials and Methods}

\subsection{Study Design}

A Cross-sectional study

\subsection{Study Period}

November 2012.

\subsection{Study area}

Three secondary Schools of North Khartoum. 


\subsection{Sampling Technique}

The Simple Random Sampling Technique was applied to select three schools from the spot map of Khartoum North for this study.

\subsection{Study Population}

Four hundred and night-one female students in the adolescent age, who were studying in these schools, participated in this study.

\subsection{Selection Criteria}

All the adolescent girl students belonging to the adolescent age group were selected for this study.

\subsection{Inclusion Criteria}

All adolescent girls studying in the selected secondary schools, and who gave informed written consent to participate in the study and were present on the day test, were included in this study,

\subsection{Exclusion Criteria}

Participants who: -are not attended the session or absent at that day, or do not want to answer the questions, or those who did not give any written informed consent.

\subsection{Data Collection Procedure}

All the participants were explained about the purpose of the study and were ensured strict confidentiality, following which verbal informed consent was taken from each of them before the interview. The participants were given the option of not participating in the study if they did not want to. Then using the GHQ technique the data were collected. Initially, all the participants were evaluated by the pre-test questionnaire. GHQ-28, and Pre-tested questionnaire were structured to be used for the student including all study variables which is completed anonymously. collectors attended all schools on the selected days, they reviewed the lists of the students who were recorded to attend this study in order to find those who were included in the sample by matching the lists with those provided by field supervisor, so that they could meet them, get their agreement to participate in the study, and fill the questionnaire Then In brief ,pre-test was done to verify the technique of the questionnaire in three secondary schools to determine the duration needed to fill questionnaire, acceptance of questions, in order to respect their time and work.

\subsection{Data Analysis}

The data collected were thoroughly cleaned and entered into Excel spread sheets, and analysis was carried out using the statistical package SPSS (Statistical Package for Social Sciences) version 10.0 for Windows. The procedures involved were transcription, preliminary data inspection, content analysis, and interpretation. 


\section{Result}

The results were calculated in terms of proportions. Proportions were used to derive information on the baseline characteristics of the participants. )The above mentioned Sociodemographic profile of the study shows the distribution factors among the population $n=491$, (table 1 ). The following cross tabulations using chi square, p-value $<0.05$, suggest that, there is relationship between the factors and psychosomatic disorder, as follows: Percentage of adolescent within the late age (18$19 \mathrm{yr}$ ) with psychosomatic disorder reported among school girls with prevalence rate $61.30 \%$, comparing with mid age group (14-17yr) $38.70 \% \mathrm{P}$ value is reported $<0.0005$, so psychosomatic disorder have statistically highly significant relationship with late adolescence girls, chi- square $=$ $18.611, \mathrm{df}=2$ (cross tabulation.4). Percentage of those who have been physical abused with psychosomatic disorder reported among school girls with prevalence rate $39.41 \%$ comparing with those who have not been physical abused with prevalence rate $60.58 \%$ and $\mathrm{P}$ value reported $<0.0005$, so there is statistically significant relation between psychosomatic and physical abused. , chi- square $=22.34, \mathrm{df}=1$ (cross tabulation.5). Percentage of those who have been abused verbal with psychosomatic disorder reported among school girls with prevalence rate $72.35 \%$ comparing with those who have not been abused verbal with prevalence rate $27.64 \%$ and $\mathrm{P}$ value reported $<0.0005$, which is is statistically highly significant relation between psychosomatic and verbal abused., chi- square $=21.86, \mathrm{df}=1$ (cross tabulation.6) . Percentage of monthly income is reported among school girls, with prevalence rate $40 \%$ for that low and moderate income compared with prevalence rate $20 \%$ from those high incomes, and $\mathrm{P}$ value is reported 0.078 , which is border line significant with family low $(40 \%)$ and moderate $(40 \%)$ income, chi- square $=5.09, \mathrm{df}=2$ crosstabulation.7)'. Percentage of married parents with psychosomatic disorder is reported among school girls with prevalence rate $83.5 \%$, comparing with those with non- psychosomatic with prevalence rate $89.02 \%$ and $\mathrm{P}$ - value reported is 0.228 , So there is no association between psychosomatic disorder and family relationship, chi- square $=2.95, \mathrm{df}=2$ (cross tabulation.8) .Percentage of High level father with psychosomatic disorder is reported among school girls with prevalence rate $72.94 \%$, comparing with other education level with prevalence rate (illiterate $5.88 \%$, elementary $21.17 \%$ ) , and $\mathrm{P}$ value reported 0.489 , then there is no association between parent education and psychosomatic disorder, chi- square $=3.17, \mathrm{df}=2$ (cross tabulation.9). .Percentage of elementary mother with psychosomatic disorder is reported among school girls with prevalence $61.90 \%$,comparing with other education level with prevalence rate (illiterate $10.00 \%$ high level $28.23 \%$, ) and $\mathrm{P}$ value is reported 0.72 , so there is no association between parent education and psychosomatic disorder chi- square $=1.692, \mathrm{df}=2$ (cross tabulation.10).

Table 1: Sociodemographic profile of the study population among Adolescent Secondary School Girls, Khartoum North locality, 2012

$(\mathrm{n}=491)$ :

\begin{tabular}{|c|c|c|c|}
\hline \multirow{2}{*}{\multicolumn{2}{|c|}{ Variables }} & \multicolumn{2}{|c|}{ Frequency } \\
\hline & & No. & $\%$ \\
\hline \multirow[t]{2}{*}{ Age } & Mid age (14-17yr) & 66 & $38.82 \%$ \\
\hline & Late age (18-19) & 104 & $61.17 \%$ \\
\hline \multirow[t]{3}{*}{ Monthly income } & "Low less than 750 SDG" & 67 & $40 \%$ \\
\hline & Moderate 750-1000 SDG & 67 & $40 \%$ \\
\hline & High more than 1000 SDG & 34 & $20 \%$ \\
\hline
\end{tabular}




\begin{tabular}{|l|l|c|c|}
\hline \multirow{3}{*}{ Father education } & Illiterate & 10 & $5.88 \%$ \\
\cline { 2 - 4 } & Elementary & 36 & $21.17 \%$ \\
\cline { 2 - 4 } & High level & 124 & $72.94 \%$ \\
\hline \multirow{3}{*}{ Mother education } & Illiterate & 17 & $10.00 \%$ \\
\cline { 2 - 4 } & Elementary & 105 & $61.76 \%$ \\
\cline { 2 - 4 } & High level & 48 & $28.23 \%$ \\
\hline \multirow{2}{*}{$\begin{array}{l}\text { Marital } \\
\text { Status }\end{array}$} & Divorced or widowed & 28 & $16.47 \%$ \\
\cline { 2 - 4 } & Married & 142 & $83.52 \%$ \\
\hline Physical abuse & 67 & $39.41 \%$ \\
\hline Verbal abuse & 123 & $72.35 \%$ \\
\hline
\end{tabular}

The above mentioned Sociodemographic profile of the study shows the distribution factors among the population $n=491$, (table 1 ). The following cross tabulations using chi square, $p$-value $<0.05$, suggest that, there is relationship between the factors and psychosomatic disorder, as follows:-

Table 2: Prevalence of Psychiatric Morbidity and Psychosomatic Disorder among Adolescent Secondary School Girls, Khartoum North locality, $2012 * 28$ G HQ $\geq 24$

$(\mathrm{N}=491)$

\begin{tabular}{|l|c|c|}
\hline & Frequency & Percent \\
\hline *Psycatric morbidity & 299 & $60.89 \%$ \\
\hline$* *$ Psychosomatic disorder & 170 & $34.62 \%$ \\
\hline Total & $469 * * *$ & $95.53 \%$ \\
\hline
\end{tabular}

1) Those whose scores $\geq 24$ when applying the $28 \mathrm{G}$ HQ scales.

2) Psychosomatic disorder $=$ Psychiatric morbidity + at least one somatic symptom.

3) Missed data.

Table 2: showed that the prevalence of psychosomatic disorder (GHQ>24) was 170 (34.62\%), and the prevalence of psychiatric disease 299 (60.89\%) (Table.2), this research using GHQ-28 investigated health situation of 491 girls, from those 170 who are complains of psychosomatic disorder. The data of this study showed the scores of all of sub-scales of 28 GHQ and cut off point 24 in psychosomatic girls.

\section{Discussions}

Study shows that the prevalence of psychosomatic disorder among the school girls adolescent (34.62\%) that goes in parallel with findings that the scores of all of sub- scales of GHQ-28 in girls are argued that psychosomatic disorder have significant relationship with late adolescence girls. The prevalence reported by this study was higher than that of Sweden (26\%). Literature in Ireland showed that there is no relationship between socioeconomic statues and psychosomatic disorder. It revealed that the girls from less affluent backgrounds were significantly more likely to report frequent symptoms (Colette Kelly, et al.20091). However, finding of this study showed border line significant of psychosomatic disorder in relation to the family income. Tuvblad et al. in the year 2006 reported that the percentage of all psychosomatic disorder' is found to be higher in low and moderate socioeconomic class as compared to high class. 
In consistency with this Literature where S.E status is a known factor for the universal studies they found same result. Percentage of psychosomatic slightly lower in families with divorced or widower (16.4\%) as compared to married (83.5\%) so there is no association between psychosomatic disorder and family relationship, confirmed by (Collins and laursen 2004) ) that parenting has been considered optimal when communication between parents and adolescents is bidirectional, parents show warmth and acceptance, encourage social responsibility while maintaining age-appropriate control and monitoring (Collins and laursen 2004). Problems in parenting behaviors have been seen as a risk factor for problem behavior (Collins and laursen 2004) and as moderators or mediators between other risk factors, such as maternal depression or economical hardship and maladjustment .Percentage of girls within the late age group increased the psychosomatic disorder more than the mid age group. So, there is statistically significant relationship between age group and psychosomatic disorder. Percentage of girls who have not been abused physically is increased the psychosomatic disorder more than those who have been abused, so there is statistically significant relation between psychosomatic and physical abused. Percentage of girls who have been abused verbally is increased with the psychosomatic disorder more than those who have not been abused so there is statistically significant relation, between psychosomatic and verbal abused. Percentage of psychosomatic is higher among higher school compared with father with lower level of education, so there is no association between parent education and psychosomatic disorder.

\section{Conclusion}

Although the finding, in this thesis is just scratching on the surface of the problems adolescents encounter in their health daily lives, they highlight the need for a multidisciplinary approach when studying their health problems. The health problems seen today are becoming more and more complex and thus need a new approach to solve as they are in many cases no longer solely medical. In conclusion, this study highlights the need for a better understanding of the nature, extent, and possible causes of frequent psychosomatic disorder among school girls in Khartoum north district. Social, environmental, and behavioral factors need further consideration. Exploring time trends in psychosomatic disorder among the girls is also worth pursing in light of the recent educational changes in Sudan. Such data would assist decision makers and those who care for children in providing the most relevant care through programs and behavioral support required. Also, prevalence of psychosomatic and psychiatric disorders is high among late adolescent girls; which associated with variable influencing factors that require further investigation.

There is strongly association between psychiatric morbidity and psychosomatic disorder among adolescence school girls with age, all somatic symptoms, and the physical and verbal abuse, and also there is borderline significant between low and moderate social classes comparing to the higher classes.

\section{Acknowledgements}

We would like to thank the data collectors and all those who supported, this work and supplied data: Planning directorate of the Federal Ministry of Health, University of Khartoum libraries, and individual researchers. 


\section{References}

[1] Steinberg H )2004(. The Sin in The Aetiological Concept of Johann Christian August Heinroth (1773-1843). Part 2: Self-Guilt as Turning Away from Reason In The Framework Of Heinroth'S Concept Of The Interrelationships Between Body And Soul. History of Psychiatry.;15(4):437-54.

[2] V. Lipowski1976.: Dist. Court, D. New Jersey;. 423 F. Supp. 864.United States

[3] 3]Robinson Dp, Greene Jw, Walker Ls. Functional Somatic Complaints In Adolescents: Relationship To Negative Life Events, Self-Concept, And Family Characteristics. The Journal Of Pediatrics. 1988;113(3):588-93.

[4] Brownr.1992, Psychosomatic Problems In Adolescents. Adolescent Medicine (Philadelphia, $\mathrm{Pa})$;3(1):87.

[5] Berntsson Lt, Gustafsson J-E. Determinants Of Psychosomatic Complaints In Swedish Schoolchildren Aged Seven To Twelve Years. Scandinavian Journal Of Public Health. 2000;28(4):283-93.

[6] Bolin Låftman S, Östberg V. The Pros and Cons Of Social Relations: An Analysis Of Adolescents' Health Complaints. Social Science \& Medicine. 2006;63(3):611-23.

[7] Kelly C, Molcho M, Doyle P, Gabhainn Sn. Psychosomatic Symptoms Among Schoolchildren. International Journal Of Adolescent Medicine And Health. 2010;22(2):229-36.

[8] Raban Mz, Dandona R, Dandona L. Essential Health Information Available for India In The Public Domain On The Internet. Bmc Public Health. 2009;9(1):208.

[9] Singh S. Singh M, Arora M (2007). Somatotype And Disease-A Review.

[10] Cavallo F, Zambon A, Borraccino A, Raven-Sieberer U, Torsheim T, Lemma P. Girls Growing Through Adolescence Have A Higher Risk Of Poor Health. Quality Of Life Research. 2006;15(10):1577-85.

[11] Alfano Ca, Ginsburg Gs, Kingery Jn. Sleep-Related Problems Among Children And Adolescents With Anxiety Disorders. Journal Of The American Academy Of Child \& Adolescent Psychiatry. 2007;46(2):224-32

[12] Ray S, Ghosh T, Mondal Pc, Basak S, Alauddin M, Choudhury Sm, Et Al. Knowledge And Information On Psychological, Physiological And Gynaecological Problems Among Adolescent Schoolgirls Of Eastern India. Ethiopian Journal Of Health Sciences. 2011;21(3).

[13] Modin B, Östberg V. School Climate And Psychosomatic Health: A Multilevel Analysis. School Effectiveness And School Improvement. 2009;20(4):433-55.

[14] Lindström A. (2011). The Ownership Of Traditional Knowledge.;29(3)

[15] Windle M, Grunbaum Ja, Elliott M, Tortolero Sr, Berry S, Gilliland J, Et Al. Healthy Passages: A Multilevel, Multimethod Longitudinal Study Of Adolescent Health. American Journal Of Preventive Medicine. 2004;27(2):164-72.

[16] Voegelin E, Germino Dl. Plato And Aristotle)2000(: University Of Missouri Press;.

[17] Hall Gs) 1996(. Adolescence: Its Psychology And Its Relations To Physiology, Anthropology, Sociology, Sex, Crime, Religion And Education: D. Appleton;.

[18] Leventhal T, Brooks-Gunn J. The Neighborhoods They Live In: The Effects Of Neighborhood Residence On Child And Adolescent Outcomes. Psychological Bulletin. 2000;126(2):309.

[19] Keating Dp)2004(. Cognitive And Brain Development. Handbook Of Adolescent Psychology:;2:45-84.

[20] Coleman Jc, Henry Lb)1999(. The Nature Of Adolescence. 3e: Psychology Press;.

[21] Larson R, Wilson S).2004(. Adolescence Across Place And Time. Handbook Of Adolescent Psychology::299-330.

[22] Fröjd S).2008(. Mental Health In Middle Adolescence. Association Of Family Factors With Diverse Maladjustment Outcomes..

[23] Ding L, Getz G, Wheeler Da, Mardis Er, Mclellan Md, Cibulskis K, Et Al. Somatic Mutations Affect Key Pathways In Lung Adenocarcinoma. Nature. 2008;455(7216):1069-75. 
[24] Coleman Jc, Hendry Lb)1999(. The Nature Of Adolescence.

[25] Field S, Hoffman A, Posch M. Self-Determination During Adolescence A Developmental Perspective. Remedial And Special Education. 1997;18(5):285-93.

[26] Mandell Ds, Walrath Cm, Goldston Db. Variation In Functioning, Psychosocial Characteristics, And Six-Month Outcomes Among Suicidal Youth In Comprehensive Community Mental Health Services. Suicide And Life-Threatening Behavior. 2006;36(3):349-62.

[27] Romano E, Tremblay Re, Vitaro F, Zoccolillo M, Pagani L)2001(. Prevalence Of Psychiatric Diagnoses And The Role Of Perceived Impairment: Findings From An Adolescent Community Sample.

[28] Pignone Mp, Gaynes Bn, Rushton Jl, Burchell Cm, Orleans Ct, Mulrow Cd, Et Al. Screening For Depression In Adults: A Summary Of The Evidence For The Us Preventive Services Task Force. Annals of Internal Medicine. 2002;136(10):765-76.

[29] Susman Ej, Rogol.A)2004(. Puberty And Psychological Development. Handbook Of Adolescent Psychology; 2:15-4.

[30] Rauste-Von Wright M, Von Wright J. A Longitudinal Study Of Psychosomatic Symptoms In Healthy 11-18 Year Old Girls And Boys. Journal Of Psychosomatic Research. 1981;25(6):525-34.

[31] Aro H, Paronen O, Aro S. Psychosomatic Symptoms Among 14-16 Year Old Finnish Adolescents. Social Psychiatry. 1987;22(3):171-6.

[32] Grøholt E-K, Stigum H, Nordhagen R, Köhler L. Recurrent Pain In Children, Socio-Economic Factors

[33] And Accumulation In Families. European Journal Of Epidemiology. 2003;18(10):965-75

*Corresponding author.

E-mail address: dr.nadiaali@ hotmail.com/kamil1952@yahoo.com 